\title{
mGluR5 Regulates Glutamate-Dependent Development of the Mouse Somatosensory Cortex
}

\author{
Lasani S. Wijetunge, Sally M. Till, Thomas H. Gillingwater, Cali A. Ingham, and Peter C. Kind \\ Centre for Integrative Physiology, University of Edinburgh, Edinburgh EH8 9XD, United Kingdom
}

We have previously reported that mGluR5 signaling via PLC- $\beta 1$ regulates the development of whisker patterns within S1 (barrel) cortex of mice (Hannan et al., 2001). However, whether these defects arise from the loss of postsynaptic mGluR5 signaling, and whether the level of mGluR5 is important for barrel formation, was not examined. Furthermore, whether mGluR5 regulates other developmental processes that occur before or after barrel development is not known. We now show that mGluR5 is present postsynaptically at thalamocortical synapses during barrel formation. In addition, $\mathrm{Mglur}^{+/-}$mice exhibit normal TCA patch formation but reduced cellular segregation in layer 4, indicating a dose-dependent role for mGluR5 in the regulation of pattern formation. Furthermore $\mathrm{Mglur}^{-1-}$ and $\mathrm{Mglur}^{+/-}$ mice display normal cortical arealization, layer formation, and size of PMBSF indicating the defects within S1 do not result from general abnormalities of cortical mapping during earlier stages of development. At P21 layer 4 neurons from Mglur $5^{-1-}$ and $M g l u r 5^{+/-}$mice show a significant reduction in spine density but normal dendritic complexity compared with $M g l u r 5^{+/+}$mice indicating a role in synaptogenesis during cortical development. Finally, mGluR5 regulates pattern formation throughout the trigeminal system of mice as the representation of the AS whiskers in the PrV, $\mathrm{VpM}$, and $\mathrm{S} 1$ cortex was disrupted in $M g l u r 5^{-I-}$ mice. Together these data indicate a key role for mGluR 5 at both early and late stages of neuronal development in the trigeminal system of mice.

Key words: mGluR5; barrel; development; dendritic spine; thalamocortical afferent; somatosensory cortex

\section{Introduction}

Synaptic activity regulates numerous aspects of neuronal development including early pattern formation in developing sensory areas, neuronal morphology, and changes in synaptic efficacy that underlie experience-dependent plasticity. Whether synaptic activity is initiated by spontaneous neuronal activity, experience, or even spontaneous release of neurotransmitter, glutamate receptors and their associated signaling pathways are key to initiating activity-dependent alterations in neuronal phenotype.

The primary somatosensory cortex (S1) of rodents provides an excellent model for investigating the cellular mechanisms that regulate glutamate-dependent development (Erzurumlu and Kind, 2001; Kind and Neumann, 2001; Barnett et al., 2006a) because of its well characterized cytoarchitectonic units known as "barrels" that recapitulate the pattern of whiskers on the rodent face-pad (Woosley and Van der Loos, 1970; Killackey and Belford, 1979). There are three key anatomical events that take place in the formation of a barrel: thalamocortical axons (TCAs) segregate into discrete barrel-like bundles in layer 4 (Rebsam et al., 2002), layer 4 neurons translocate to form a cell-dense barrel wall and a cell-sparse barrel hollow, and dendrites of layer 4 neurons selectively elaborate in the associated TCA patch and retract their

Received June 6, 2008; revised 0ct. 8, 2008; accepted 0ct. 11, 2008.

This work was supported by the Medical Research Council, UK (P.C.K.), the Wellcome Trust, and the Fragile X Research Foundation (P.C.K., S.M.T.). We thank Trudi Gillespie for her expertise and help with the confocal microscopy and Alex Crocker-Buque for his help with the statistical analysis.

Correspondence should be addressed to Peter C. Kind, University of Edinburgh, Centre for Integrative Physiology, Hugh Robson Building, George Square, Edinburgh EH8 9XD, UK. E-mail: pkind@ed.ac.uk.

DOI:10.1523/JNEUROSCI.2600-08.2008

Copyright $\odot 2008$ Society for Neuroscience ～0270-6474/08/2813028-10\$15.00/0 branches from outside the patch, to give rise to oriented dendritic trees (Woolsey and Van der Loos, 1970).

All three of these steps are dependent on glutamatergic transmission. Both NMDA receptors and metabotropic glutamate receptor 5 (mGluR5) regulate barrel development (Iwasato et al., 2000; Hannan et al., 2001). Cortex specific deletion of the NR1 subunit of NMDA receptors results in the complete absence of cellular segregation, rudimentary segregation of TCAs, an increase layer 4 dendritic complexity and spine density and exuberant TCA arbor elaboration outside layer 4 (Iwasato et al., 2000, Datwani et al., 2002, Lee et al., 2005). Similarly, Hannan et al. (2001) reported that mice lacking either mGluR5 or its downstream target enzyme, phospholipase C- $\beta 1$ (PLC- $\beta 1$ ), exhibit a complete loss of cellular segregation despite partial or normal segregation of TCA patches, respectively. While a role for mGluR5 in dendritogenesis and spinogenesis has not been examined, several lines of evidence suggest such a role may exist. For example, in vitro stimulation of hippocampal neuronal cultures with group 1 mGluR agonist (S)-3,5-dihydroxyphenylglycine (DHPG) has shown increased frequency of elongated spines (Vanderklish and Edelman, 2002). Furthermore, Plc- $\beta 1$ null mutant mice show an overall decrease in the number of synapses per neuron in layers 2-4 and apical dendrites of layer 5 pyramidal neurons in these mutants show a decrease in the density of mushroom spines indicating a defect in spine maturation (Spires et al., 2005).

This manuscript builds on previous findings that $\mathrm{Mglur}^{-{ }^{--}}$ mice exhibit abnormal morphological development of S1 (Hannan et al., 2001). We now demonstrate that this regulation of map development arises from the loss of mGluR5 postsynaptically, is 
A

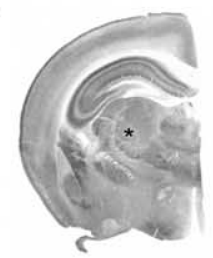

$\mathrm{D}$

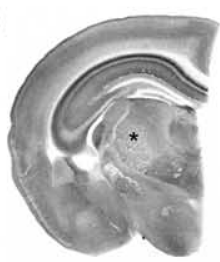

G

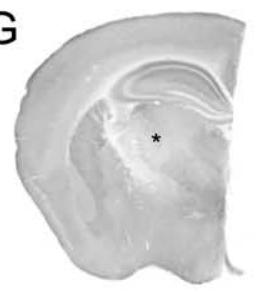

$J$
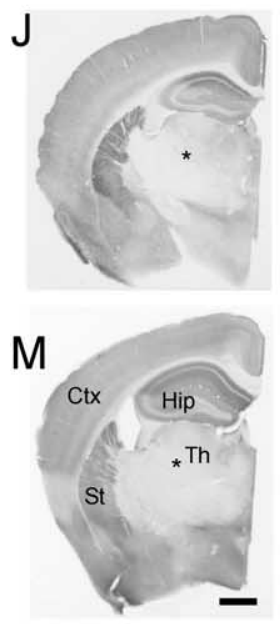
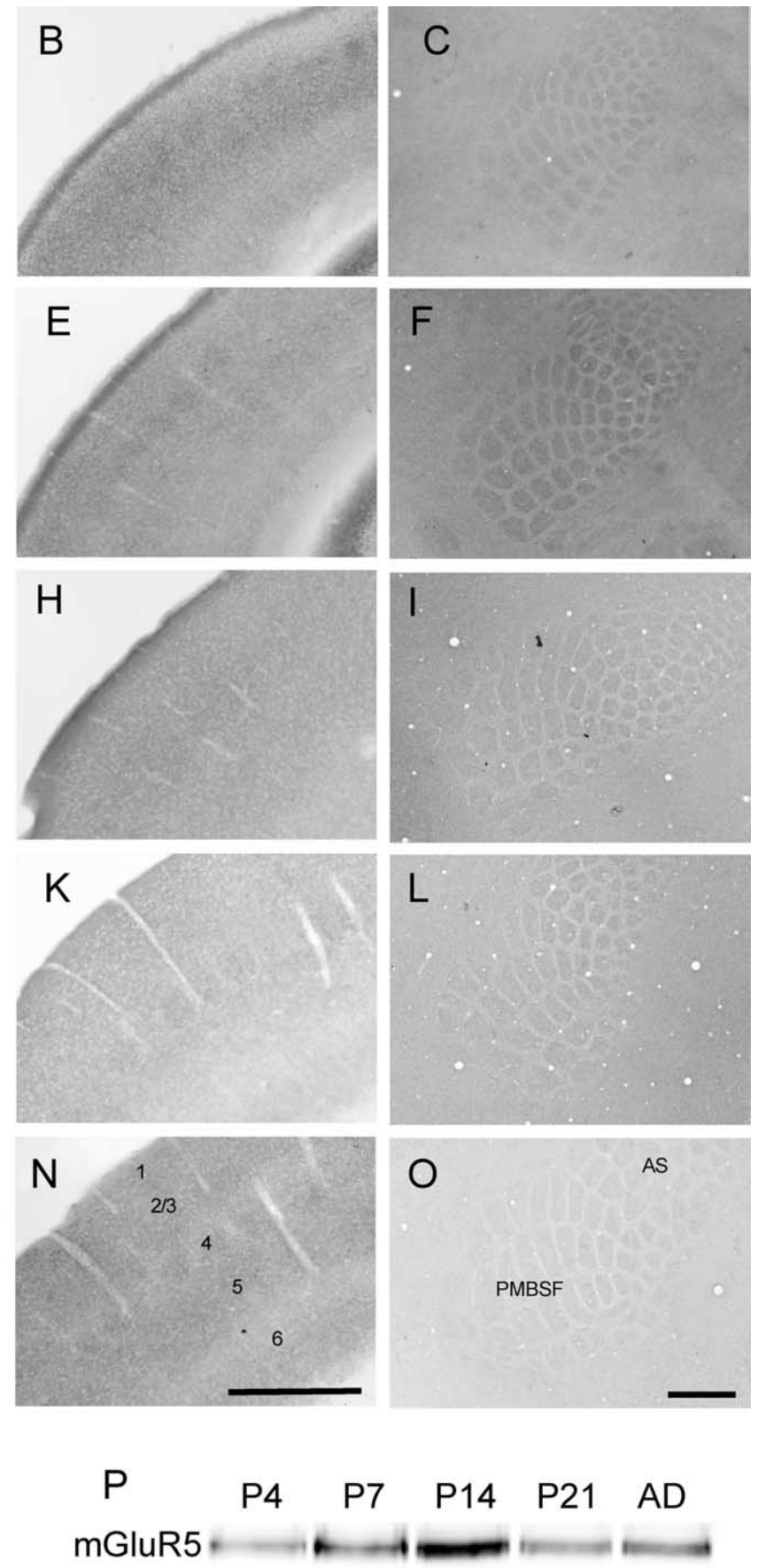

Figure 1. Developmental expression profile of mGluR5. Immunohistochemical localization of mGluR5 in P4 (A-C), P7 (D-F), P14 (G-I), P21 (J-L), and adult $(\boldsymbol{M}-\mathbf{O})$ animals. At all ages, mGluR5 is present throughout the cortex $(\boldsymbol{B}, \boldsymbol{E}, \boldsymbol{H}, \boldsymbol{K}, \boldsymbol{N})$ with patches corresponding to whisker representations visible in tangential sections through layer 4 of $S 1(C, F, I, L, 0)$. Although staining in the cortex remains high throughout development, Western blot analysis of barrel cortex homogenates shows that peak expression occurs at P14 (P). In contrast, staining in the thalamus, including VpM (asterisks), shows an age-dependent decline in mGluR5 immunoreactivity with high levels from P4 to P14 but no detectable mGluR5 at P21. No immunostaining was visible in Mglur5 $^{-1-}$ animals, indicating that the staining is specific for mGluR5 (data not shown). Scale bars, $500 \mu \mathrm{m}$.

\section{Materials and Methods}

Transgenic animals. Mglur5 mutant mice were obtained from Jackson Laboratories and bred from $\mathrm{Mglur}^{+/-}$heterozygous breeding pairs on a mixed C57BL/6JX129 background. The presence or absence of the Mglur5 ${ }^{-}$allele was determined by PCR using primers PGK22N (5'-AGG GGA GGA GTA GAA GGT GGC GCG A), F (5'-GCT CAC ATG CCA GGT GAC ATT ATT ATT GGA), and R (5'-CCA TGC TAG TTG TTG CAG AGT AAG CAA TCT GAG GT) (MWG). The WT and KO PCR products were run as two separate reactions using the PCR program: $95^{\circ} \mathrm{C}$ for $10 \mathrm{~min}$, followed by 30 cycles of amplification where each cycle comprised of $5 \mathrm{~s}$ at $95^{\circ} \mathrm{C}, 55 \mathrm{~s}$ at $64^{\circ} \mathrm{C}$, and $30 \mathrm{~s}$ at $72^{\circ} \mathrm{C}$. The PCR products were WT (F/R) $445 \mathrm{bp}$ and $\mathrm{KO}(\mathrm{F} / \mathrm{PGK} 22 \mathrm{~N})$ of $\sim 600 \mathrm{bp}$.

Tissue preparation for histology. All mice used for histology were given a lethal dose of sodium pentobarbital (Euthanol; $200 \mathrm{mg} / \mathrm{kg}$, i.p.) and perfused transcardially with saline followed by $4 \%(\mathrm{w} / \mathrm{v})$ paraformaldehyde in $0.1 \mathrm{~m}$ phosphate buffer (PB). The brains were removed, postfixed in $4 \%$ paraformaldehyde for at least $6 \mathrm{~h}$ and cryoprotected overnight in $30 \%(\mathrm{w} / \mathrm{v}) \mathrm{su}-$ crose in PBS. Brains were sectioned either in the coronal plane or tangential to the pial surface on a freezing microtome at $48 \mu \mathrm{m}$ thickness unless otherwise specified. Two different flattening techniques were used depending on the aspect of cortical development being analyzed. For mGluR5 developmental expression profile, quantification of cellular segregation and Golgi analysis in layer 4 , the cortices were separated and the thalamus, entorhinal cortex, hippocampus, and striatum were dissected leaving only the neocortical sheet. This procedure removes all connections that could distort the barrel pattern during flattening. For cortical and $\mathrm{S} 1$ measurements and positioning of posterior medial barrel subfield (PMBSF), the cortices were separated, thalamus (and part of the striatum) removed and cortex was gently pressed between two glass slides using capillary tubes as spacers. Tissue was flattened fixed in this position for at least $24 \mathrm{~h}$ before processing tissue as described above. This procedure keeps valuable landmarks intact for accurately determining the relative position of $\mathrm{S} 1$.

Histology and immunohistochemistry. For the mGluR5 developmental expression profile, brains were collected from P4, P7, P14, P21, and $\mathrm{AD}$ wild-type (WT) mice. Both coronal and tangential free-floating sections were reacted with anti-mGluR5 (1:10,000; Millipore). For cortical lamination measurements, coronal sections were stained with thionin acetate $(0.5 \%)$ to demarcate the cortical layers. Adjacent sections were reacted with anti-calretinin (1:2000; Swant) to delineate the layer $4 / 5$ boundary as reported previously (Watson et al., 2006). Tan- dose-dependent and does not arise from a general retardation of cortical development. We also demonstrate a role for mGluR5 in later stages of neuronal development, namely in the regulation of spine density. Together these data further elucidate the cellular mechanisms by which glutamate regulates neuronal development. gential sections used for S1 area measurements and positioning of PMBSF were reacted with anti-serotonin transporter (5-HTT) (1:2000; Calbiochem). For cell counts, tangential free floating sections were incubated in anti-5-HTT overnight and visualized using an AlexaFluor 568conjugated goat anti-rabbit secondary antibody (1:200, Invitrogen) followed by incubation in Topro-3 (1:1000, Invitrogen) in 9:1 glycerol:PBS 

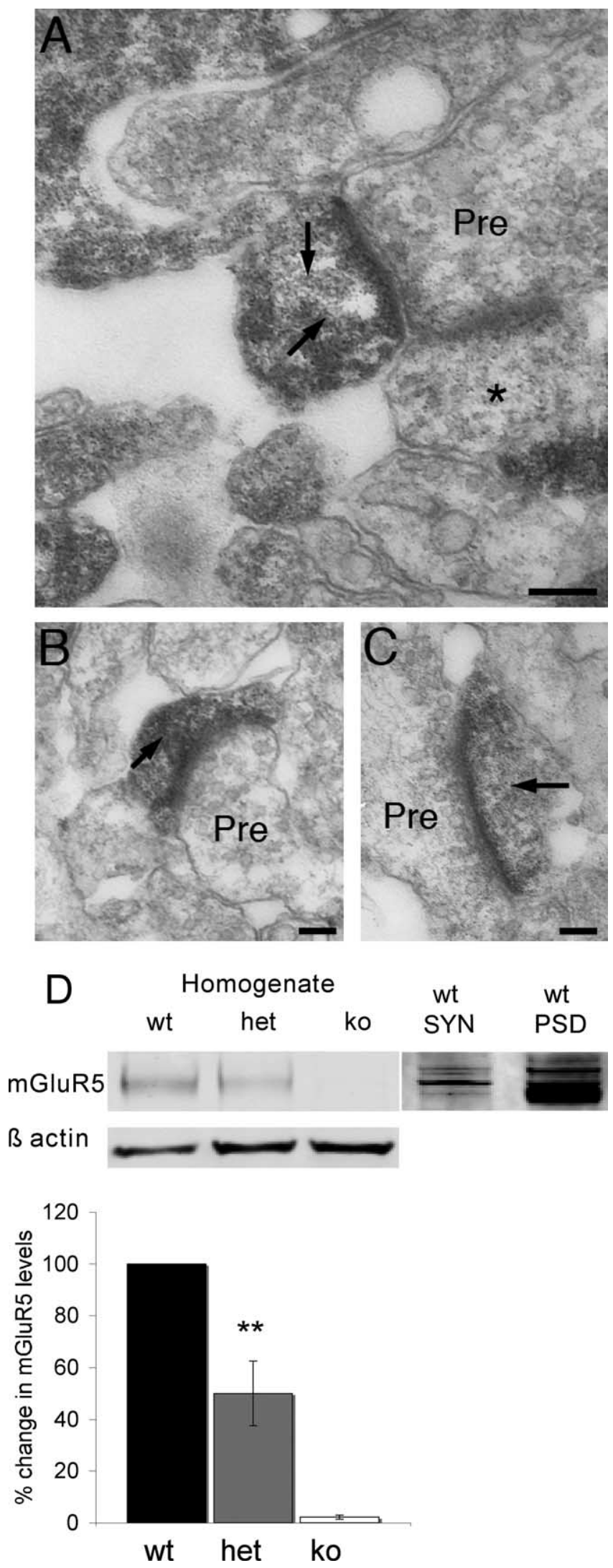

Figure 2. mGluR5 is postsynaptic in layer 4 of the primary somatosensory cortex. Immunoelectron micrographs $(\boldsymbol{A}-\boldsymbol{C})$ show that mGluR5 immunoreactivity (arrows) is restricted to PSDs and dendrites at P7. No labeled presynaptic elements were observed as identified by the presence of synaptic vesicles. mGluR5 negative synapses were also visible (asterisks) adjacent to labeled synapses indicating that mGluR5 is only present in a subset of synapses. $\boldsymbol{D}$, Western blot analysis of neocortical homogenates showing that Mglur $5^{-1-}$ animals do not express mGluR5, overnight. The sections were then mounted on Mowiol and coverslipped. For visualizing whisker-related patterns in the thalamus and brainstem (i.e., barreloids and barrelettes, respectively) cytochrome oxidase histochemistry was performed as described by Wong-Riley (1979) on $48 \mu \mathrm{m}$ coronal sections.

Measurements. All measurements were done blind to the genotype. Cortical thickness measurements were performed in coronal sections containing the anterior snout (AS) region and sections containing the PMBSF as reported previously (Barnett et al., 2006b; Watson et al., 2006). All layer and area measurements were done using UTHSCSA Imagetool version 3.0 software (University of Texas Health Science Centre at San Antonio). Each image measurement was calibrated using a $1 \mathrm{~mm}$ graticule (Graticules). Results are presented as mean \pm SEM. All measurements were analyzed using an ANOVA.

Cell counts. Cell counts were performed blind to the genotype as previously described by Watson et al. (2006) and Barnett et al. (2006b). Briefly, Topro-3-stained tangential sections through barrel C3 were imaged at $7 \mu \mathrm{m}$ intervals using a Leica confocal microscope. Morphometric analysis was performed on the optical slice containing optimal C3 segregation. Cell nuclei from barrel wall and hollow were counted to determine the ratio of cell density of the barrel wall to hollow for each $2.45 \mu \mathrm{m}$ optical slice. Results are presented as means of average densities \pm SEM and analyzed using a two-tailed $t$ test.

Immunoelectron microscopy. Immunoelectron microscopy for the localization of mGluR5 was performed on layer 4 from P7 WT animal according to the methods in Watson et al. (2006).

Golgi. Animals were perfused at P21-P23 as described above. Fixed tissue was sectioned tangentially at $80 \mu \mathrm{m}$ thickness on a vibratome. Sections were postfixed in $1 \%$ osmium tetroxide in $0.1 \mathrm{M} \mathrm{PB}$ for $30 \mathrm{~min}$ to $1 \mathrm{~h}$, washed in $0.1 \mathrm{M} \mathrm{PB}$, and those containing barrels were treated with $3.5 \%$ potassium dichromate overnight followed by an incubation in $1.5 \%$ aqueous silver nitrate for $\sim 6 \mathrm{~h}$. Sections were mounted and dehydrated in an ascending series of alcohol, followed by defatting in xylene, and coverslipped.

Dendritic complexity analysis and spine counts. All analysis was performed blind to the genotype. Neurons and dendrites were examined and traced using a Leica DMR microscope attached to a Neurolucida computer assisted tracing system (Microbrightfield). Layer 4 spiny neurons with cell bodies located at least $20 \mu \mathrm{m}$ below the surface of the section and with dendrites that could be clearly distinguished from neighboring cells were selected from the PMBSF for dendritic analysis. Dendrites were reconstructed in three dimensions under $100 \times$ oil-immersion objective and dendrite parameters were calculated using NeuroExplorer software. Dendritic measures were only analyzed for neurons having 30\% or more normal, tapered dendritic endings. For all dendritic spine analysis, only layer 4 spiny cells impregnated within the PMBSF area with a dendrite that could be traced along its entire length to its normal tapered ending were selected. The whole length of the dendrite was traced under $100 \times$ oil-immersion objective (1000× magnification) and different markers were used to denote the appearance of branch points and spines along the length of the dendrite to analyze the spine density profile (spines per 10 $\mu \mathrm{m})$. Only one dendrite was analyzed per cell, and three independent cells were analyzed for each animal. Statistical analysis was performed using an ANOVA with a post hoc Bonferroni test.

Biochemistry. For the mGluR5 developmental expression profile, WT mice were killed either by decapitation or cervical dislocation at P4, P7, $\mathrm{P} 14, \mathrm{P} 21$, and $\mathrm{AD}$, and barrel cortex was dissected out and immediately frozen on dry ice to be stored at $-70^{\circ} \mathrm{C}$. Tissue preparation and Western blot analysis was performed according to the methods outlined in Watson et al. (2006). To investigate the expression of synaptic markers in the mGluR5 mutant, P7 mGluR5 mice were killed, and synaptosome and

$\leftarrow$

and that as expected, Mglur $5^{+/-}$animals have $50 \%$ less mGluR5 compared with controls $(50 \% \pm 12.5, n=3 ; p=0.003$, two-tailed $t$ test) (asterisks in $\boldsymbol{D}$ indicate statistical significance). Analysis of synaptosomes (SYN) and PSD preparations confirm the presence of mGluR5 in PSDs (D). Scale bars: $A, 250 \mathrm{~nm} ; \boldsymbol{B}, C, 200 \mathrm{~nm}$. wt $=M g l u r 5^{+/+}$, het $=M g l u r 5^{+/-}$, and $\mathrm{k} 0=$ Mglur5 $^{-I-}$. 
A

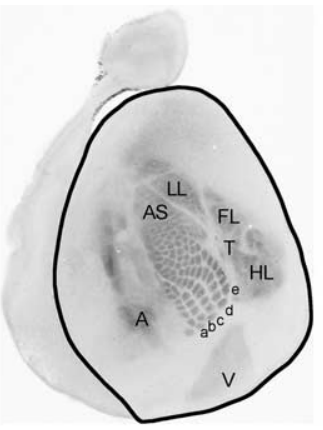

B

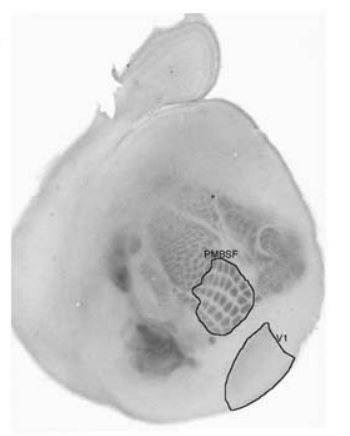

$\mathrm{F}$
C

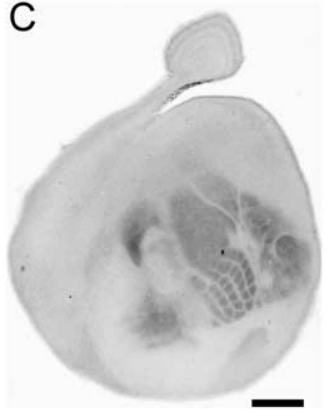

D

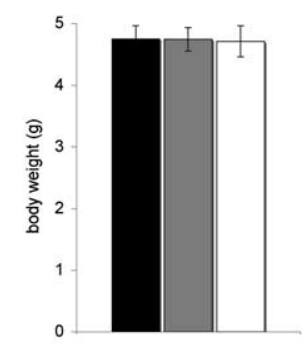

$E_{30}$
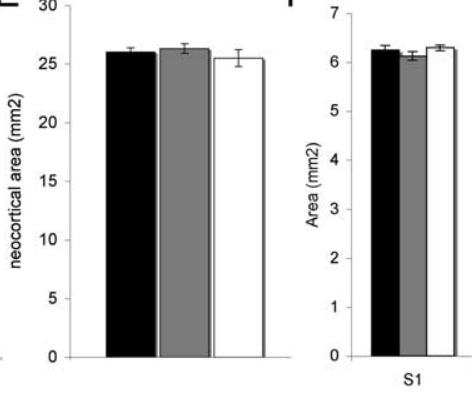

$\mathrm{H}$
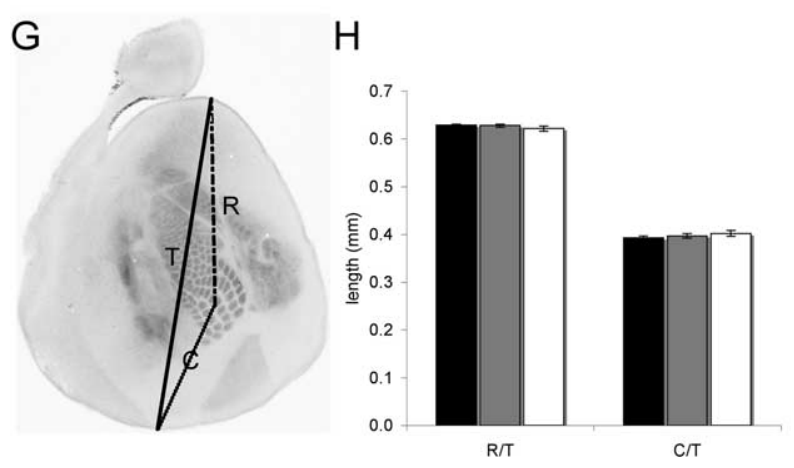

Figure 3. Loss of mGluR5 does not disrupt cortical arealization. Flattened sections through layer 4 of P7 Mglur5 ${ }^{+/+}(n=6)$ $(\boldsymbol{A})$, Mglur5 $^{+/-}(n=9)(\boldsymbol{B})$, and Mglur5 $5^{-\prime-}(n=9)(\boldsymbol{C})$ animals immunostained for 5 -HTT to reveal thalamocortical afferents (TCA). The neocortex is outlined in A. TCA patch segregation appears to be normal in Mglur5 ${ }^{+/-}(\boldsymbol{B})$. However, in Mglur5 $5^{-1-}$ animals $(C), 5-H T T$ staining is uniform in the anterior snout region (AS) indicating a lack of whisker-specific segregation. Although TCA patches are visible in PMBSF, their segregation appears reduced compared with $M g l u r 5^{+/+}$and $\mathrm{Mglur}^{+/-}$animals. The primary visual $(\mathrm{V})$, auditory $(\mathrm{A})$, and somatosensory cortex (remaining regions) are clearly visible indicating that $\mathrm{mGluR} 5$ does not regulate TCA path finding. Body weight $(\boldsymbol{D})$, neocortical area $(\boldsymbol{E})$, and area of S1, PMBSF and visual cortex ( $\boldsymbol{F}$, boundaries for these areas are shown in $A$ and $B$ ) are comparable among all genotypes. Similarly, the relative rostral (R)/caudal (C) position of $S 1$ within the neocortical sheet is unaltered in Mglur5 ${ }^{+/-}$and $M g l u r 5^{-/-}$mice $(\boldsymbol{G}, \boldsymbol{H})$, indicating that the changes in pattern formation in mGluR5 mutant mice do not arise from a general delay in cortical development. Scale bar, $1 \mathrm{~mm}$. wt $=M g / u r 5^{+/+}$, het $=$ Mglur5 $^{+/-}$, and ko $=$Mglur5 $5^{-1-}$.

postsynaptic density (PSD) preparation from neocortices were performed as described by Barnett et al. (2006b). Western blotting was performed as mentioned above and membranes were probed with antibodies against mGluR5 (1:4000, Neuromics), NR2B (1:1000; BD Transduction Laboratories), PSD-95 (1:10,000; Upstate), SAP102 (1:1000; Santa Cruz Biotechnology), Synaptophysin (1:1000; Synaptic Systems), SynGAP (1:4000; Affinity Bioreagents), PKARII $\beta$ (1:10,000; BD Transduction Laboratories), and PLC $\beta 1$ (1:8000; Santa Cruz Biotechnology). $\beta$-Actin (1:2500; Abcam) was used as the loading control. The probed membranes were visualized using fluorescently coupled appropriate secondary antibodies (1:10,000; Invitrogen) and imaged on the LiCOR Odyssey imaging system and densitometry was performed using NIH Image J gel analyzer software. The expression levels of each of these proteins of interest were normalized to that of $\beta$-actin and data are presented for Mglur5 ${ }^{+/-}$and Mglur $5^{-1-}$ mice normalized to mean Mglur $^{+/+}$. Statistical analysis was performed using an ANOVA with a post hoc Fisher's LSD test.

\section{Results}

We have previously shown that Mglur5 null mutant mice show defects in barrel development (Hannan et al., 2001). We hypothesized that these defects were due to aberrant postsynaptic signaling in layer 4 neurons. As a first step toward addressing this hypothesis, we examined the laminar expression profile of mGluR5 in the cortex throughout development by immunostaining for mGluR5. Staining was seen in all cortical layers at all ages tested (from P4 to adult) (Fig. 1A-O). Furthermore, in tangential sections through layer 4 , a barrel-like pattern was visible as early as P4 (Fig. 1C) and continued into adulthood (Fig. 1O). Western blot analysis of mGluR5 staining also showed expression in cortical homogenates at all ages examined with levels peaking at P14 (Fig. 1P), correlating well with the peak time of synaptogenesis (White et al., 1997) and experience-dependent spine plasticity (Lendvai et al., 2000). No staining was seen on sections from Mglur5 null mutants (data not shown) indicating that the immunoreactivity is specific for mGluR5. In contrast mGluR5 was expressed in ventroposterior medial (VpM) nucleus and other thalamic nuclei from P4 to P14 (Fig. $1 A, D, G)$ after which it was reduced below the levels of detection (Fig. $1 J, M$ ). Since Muñoz et al. (1999) did not examine mGluR5 expression in PrV before P9, we examined mGluR5 staining in this nucleus when barrelettes are forming. Indeed mGluR5 is heavily expressed throughout $\mathrm{PrV}$ at all stages of development examined (supplemental Fig. 3, available at www. jneurosci.org as supplemental material).

Previous reports have indicated that mGluR5 expression is mainly postsynaptic in adult cortex (Romano et al., 2001). However, the presence of mGluR5 patches at P4 (after TCA segregation but before the cellular aggregates appear) and the transient expression of mGluR5 in VpM, raises the possibility that mGluR5 is transiently expressed in TCAs during barrel formation. Furthermore, a study using synaptosomes preparations indicated a presynaptic expression of a group $1 \mathrm{mGluR}$ in cortex in juvenile (P21) mice (Rodríguez-Moreno et al., 1998). To determine the subcellular localization of mGluR5, we performed immunoelectron microscopy on sections from P7 mice (Fig. 2). At this age in layer 4, mGluR5 is heavily expressed in the PSD and dendrites. Biochemical analysis showed that mGluR5 is present in synaptosomes prepared from P7 neocortex and enriched in the PSD (Fig. 2D). We prepare our synaptosomes using a strong homogenization according to the methods of Dunkley et al. (1986) leaving a presynaptic terminal with only a PSD attached (i.e., no postsynaptic terminal) (Barnett et al., 2006b). When combined with data from immunoelectron microscopy, these data strongly suggest the 
presence of mGluR5 within the PSD and indicate a postsynaptic mode of action for the protein in barrel formation. The presence of mGluR5 positive patches at P4 therefore likely reflects either an activity dependent expression of mGluR5 selectively in dendrites contacted by TCAs or the first indication of a selective elaboration of dendrites within the TCA patches.

Hannan et al. (2001) reported that in Mglur5 $5^{-1-}$ mice, there was a complete absence of cellular segregation and TCAs formed rows but not whisker-specific patches in layer 4 of S1. However, mGluR5 is expressed in the neocortex in newborn animals (Muñoz et al., 1999) raising the possibility that mGluR5 may be regulating early events of cortical development such as cell migration and cortical patterning. Furthermore, whether there was a dosedependent effect of mGluR5 was not examined. To address these issues, we first examined the levels of mGluR5 protein in heterozygous animals. Neocortical homogenates from P7 Mglur5 ${ }^{+/-}$mice showed a $50 \%$ reduction in mGluR 5 protein levels compared with WT animals. No mGluR5 protein was detected in Mglur5 $^{-1-}$ animals (Fig. 2D). To determine whether the loss or reduction of mGluR5 affected general body and/or brain development (Fig. 3), we next examined body weight (Fig. 3D), neocortical area (Fig. 3E), cortical thickness, and the relative thickness of layer $1-4$ (supplemental Fig. 1, available at www.jneurosci. org as supplemental material). No difference was seen in any parameter in Mglur5 $^{+/-}$or Mglur5 ${ }^{-/-}$mice compared with WT animals. To determine whether mGluR5 regulates the tangential patterning of the cerebral cortex, we next examined the area of the neocortex, the size of $S 1$, the size of PMBSF or PMBSF+AS, the size of primary visual cortex (V1) (Fig. 3F), and the position of S1 within the cortical sheet in 5-HTT-stained flattened sections from WT, $\mathrm{Mglur}^{+/-}$, and Mglur5 ${ }^{-1-}$ mice (Fig. 3). No difference was seen in any of these parameters indicating that mGluR5 does not regulate the patterning or lamination of the neocortex.

No difference in the patterns of TCAs was observed between $\mathrm{Mglur5}^{+/+}$and $\mathrm{Mglur5} 5^{+/-}$mice indicating that a 50\% reduction in mGluR5 protein levels does not alter TCA patterning. In contrast to our previous findings that TCAs formed stripes corresponding to whisker rows in Mglur $5^{-1-}$ animals (Hannan et al., 2001), we observed TCA patches in PMBSF of $>20 \mathrm{Mglur}^{-1-}$ mice analyzed at P7 (Fig. $3 C$ ). In all cases, these patches were not as clearly defined as those present in either $\mathrm{Mglur}^{+/+}$or $\mathrm{Mglur}^{+/-}$mice and no patches were visible in the AS region. We previously reported that the precise barrel phenotype in Mglur5 ${ }^{-1-}$ mice is dependent on background strain. Therefore the variable expressivity of the TCA segregation phenotype may result from a shift in the relative percentage contribution of C57BL/6J and 129 backgrounds in our colony. The loss of cellular ko $=$ Mglur5 $5^{-1-}$.
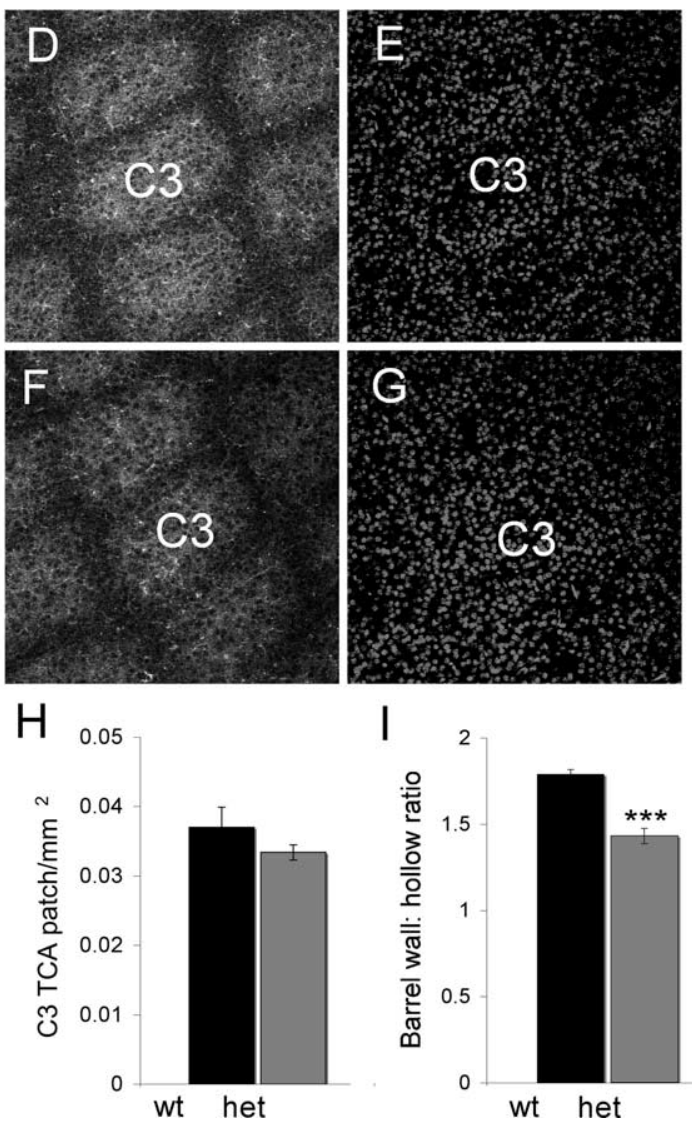

Figure 4. Barrel segregation is reduced in Mglur $5^{+/-}$animals. Thionin-stained sections through layer 4 of $M g l u r 5^{+/+}(\boldsymbol{A})$, Mglur5 $5^{+/-}(B)$, and Mglur5 $5^{-1-}(\boldsymbol{C})$ animals confirms a dramatic reduction of cellular segregation in Mglur $5^{-1-}$ animals and demonstrates reduced segregation in Mglur5 $5^{+/-}$animals. The reduction in Mglur5 ${ }^{+/-}$animals was confirmed quantitatively ${\text { Mglur } 5^{+/-}}^{+} .43 \pm 0.04 ; p=0.0001$, two-tailed $t$ test (asterisks in I indicate statistical significance)]. Density measurements were made in Mglur5 $5^{+/+}(n=5)(\boldsymbol{D}, \boldsymbol{E})$ and $M g l u r 5^{+/-}(n=11)(\boldsymbol{F}, \boldsymbol{G})$ animals using $2.45 \mu \mathrm{m}$ confocal optical sections stained Mglur $5^{+/-}$animals $(\boldsymbol{H})$. Scale bars: $\boldsymbol{C}($ for $\boldsymbol{A}-\boldsymbol{C}), 500 \mu \mathrm{m} ; \boldsymbol{G}$ (for $\left.\boldsymbol{D}-\mathbf{G}\right), 130 \mu \mathrm{m}$. wt $=$ Mglur5 ${ }^{+/+}$, het $=M g l u r 5^{+/-}$, and

segregation despite the presence of whisker related patches is similar to the phenotype seen in other laboratories using the C57BL/6J inbred colony (Hannan et al., 2001) (H.-C. Lu, personal communication) suggesting that over the last 6 years of breeding we have inadvertently biased our colony toward one with a greater contribution of C57BL/6J. Regardless of the degree of TCA segregation, the variable expressivity does not alter our main conclusion that mGluR5 plays a key role in a multifactorial process that culminates in whisker-related pattern formation.

Since there appeared to be a change, albeit a minor one in the TCA phenotype in our mGluR5 colony, and to determine whether there was a dose dependent effect of mGluR5 expression on cortical segregation, we examined the cellular distribution of layer 4 neurons in Mglur5 $5^{-/-}$, Mglur5 $^{+/-}$, and $\mathrm{Mglur5}^{+/+}$animals at P7. We also examined Mglur5 ${ }^{-1-}$ mice at P14 and P21 to determine whether the loss of barrels at $\mathrm{P} 7$ reflected a delay in barrel development. As reported previously by Hannan et al. (2001), Mglur5 ${ }^{-1-}$ mice showed near complete loss of cellular segregation through layer 4 at P7 (Fig. 4C). Segregation is so poor that although a hint of cellular segregation is visible, it is not clear in which region of S1 this occurs. Similarly near complete loss of segregation was visible at P14 or P21 (supplemental Fig. 2, available at www.jneurosci.org as supplemental material) indicating 

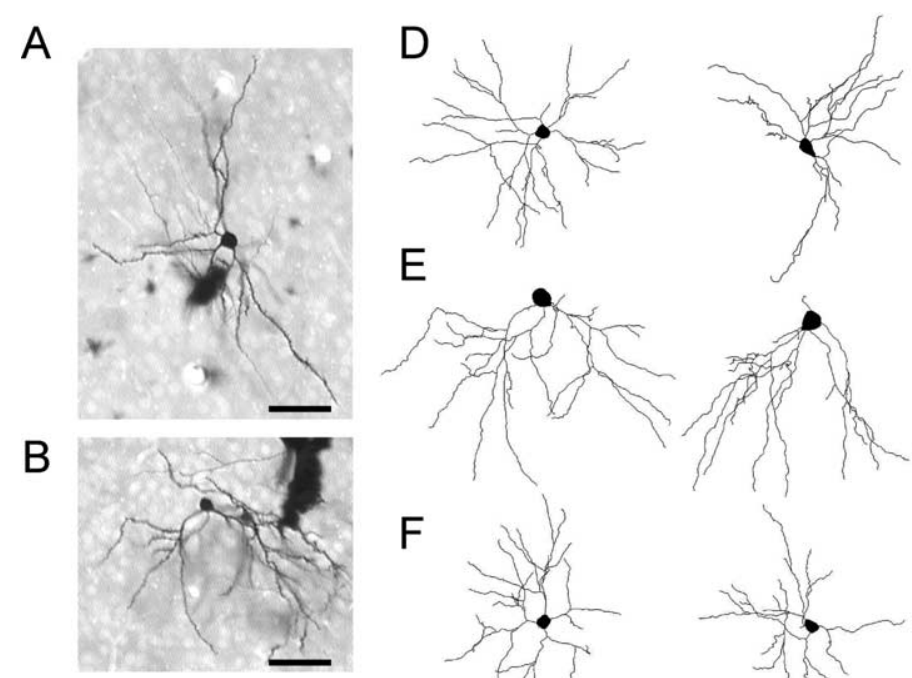

C

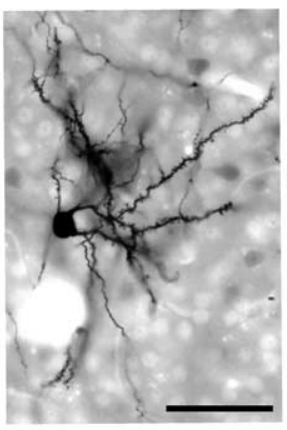

S
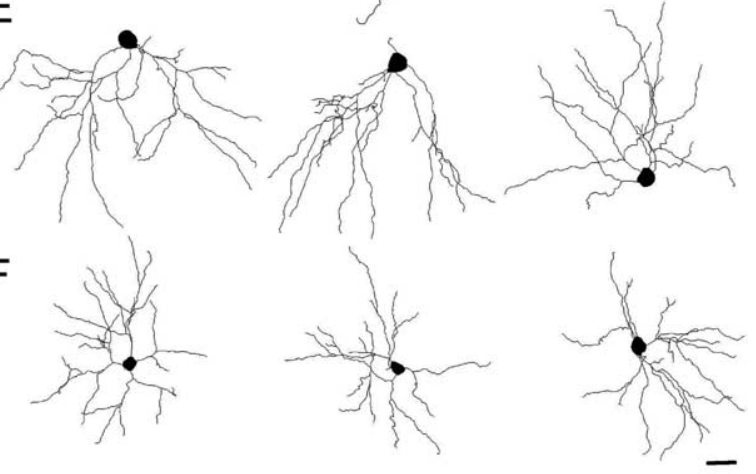

G
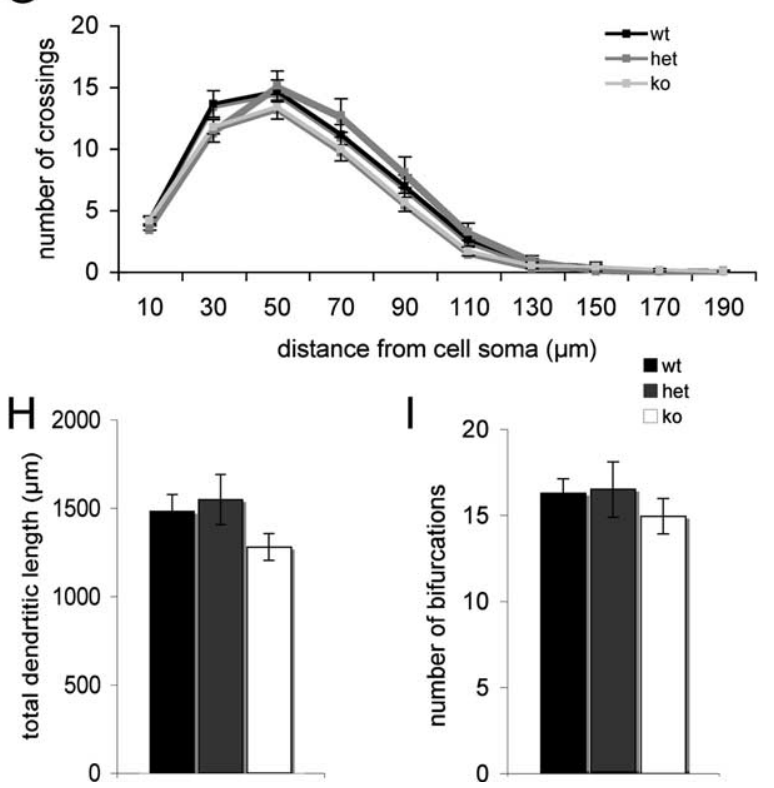

Figure 5. mGluR5 deletion does not alter dendritic complexity. Representative images of Golgi-stained isolated neurons in tangential sections through layer 4 of the primary somatosensory cortex in Mglur5 $5^{+/+}(\boldsymbol{A}), \mathrm{Mglur}^{+/-}(\boldsymbol{B})$, and Mglur5 $5^{-1-}(\boldsymbol{C})$ animals. Example traces of Neurolucida reconstructed neurons from Mglur5 ${ }^{+/+}(n=17)(\boldsymbol{D}), \mathrm{Mglur5}^{+/-}(n=18)(\boldsymbol{E})$, and Mglur5 $^{-I-}(n=18)(\boldsymbol{F})$ animals. Scholl analysis showed no difference in dendritic branching as assessed by the number of crossings $(\boldsymbol{G})$. Total dendritic length $(\boldsymbol{H})$ and number of bifurcations $(\boldsymbol{I})$ were also comparable in all groups analyzed. Scale bars: $\boldsymbol{A}-\boldsymbol{C}, 50 \mu \mathrm{m} ; \boldsymbol{F}$ (for $\boldsymbol{D}-\boldsymbol{F}), 20 \mu \mathrm{m}$. wt $=M g l u r 5^{+/+}$, het $=M g l u r 5^{+/-}$, and ko $=M_{\text {glur }} 5^{-1-}$.

that the loss of mGluR5 prevents barrel development. In $\mathrm{Mglur}^{+/-}$mice, cellular segregation also appeared to be reduced in thionin-stained tangential sections relative to that seen in $\mathrm{Mglur}^{+/+}$animals (Fig. 4A,B). To quantify the level of segregation, we double labeled flattened sections from P7 WT and Mglur $^{+/-}$animals with Topro-3 to label all nuclei and 5-HTT to label TCA patches to identify barrel walls and hollows (Barnett et al., 2006b; Watson et al., 2006). Mglur $5^{+/-}$mice showed a significantly reduced cellular segregation in layer 4 compared with $\mathrm{Mglur}^{+/+}$animals indicating a dose-dependent effect of mGluR5 in regulating S1 development (Fig. 4D-G). Measurement of the ratio of neuronal density in the barrel wall to barrel hollow showed a significant difference between $\mathrm{Mglur}^{+/+}$

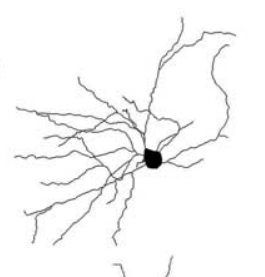

$(1.79 \pm 0.02 ; n=5)$ and Mglur5 $^{+/-}$ $(1.43 \pm 0.04 ; n=11)$ animals using a twotailed $t$ test $(p=0.0001)$ (Fig. $4 H)$.

We next examined whether mGluR5 regulates the elaboration of dendrites or spinogenesis in developing layer 4 neurons. We used Golgi staining to examine layer 4 neurons in tangential sections through S1 to quantify dendritic complexity in WT and mutant animals (Fig. 5). Scholl analysis revealed no significant differences in the number of dendrite crossings with increasing distance from the cell soma as a function of genotype (Fig. $5 G$ ). Similarly analysis of total dendritic length (Fig. $5 H$ ) or number of bifurcations (Fig. 5I) showed no significant differences between genotypes indicating that mGluR5 does not regulate dendritic elaboration and complexity. In contrast, analysis of spine density showed a significant reduction in the density of spines in both Mglur5 $^{+/-}$and Mglur5 ${ }^{-1-}$ mice compared with $\mathrm{Mglur}^{+/+}$mice (Fig. 6A-C). This decrease in spine density occurred over the entire length of the dendrite for both $\mathrm{Mglur}^{+/-}$and $\mathrm{Mglur}^{-1-}$ mice (Fig. 6B) relative to $\mathrm{Mglur}^{+/+}$mice. In agreement with the decrease density of spines, we also observed a decrease in the level of many postsynaptic markers in neocortical homogenates for both Mglur5 ${ }^{+/-}$ and $\mathrm{Mglur}^{-1-}$ mice (Fig. 6D). NR2B, SAP-102, PSD-95, and synaptophysin were all significantly reduced in $\mathrm{Mglur5}^{+/-}$and $\mathrm{Mglur}^{-1-}$ mice compared with $\mathrm{Mglur}^{+/+}$controls. Levels of SynGAP, PLC- $\beta 1$, and PKARII $\beta$ did not significantly differ from WT animals.

Finally, the loss of TCA segregation in the AS region of $\mathrm{S} 1$ and the high levels of mGluR5 in VpM and PrV during development led us to examine segregation of whisker-related patterns in the thalamus and brainstem, respectively. Clear barrelettes were visible throughout the principal trigeminal nucleus of the brainstem $(\mathrm{PrV})$ of all $\mathrm{Mglur}^{+/+}(n=2)$ and Mglur5 $^{+/-}(n=9)$ mice examined. In contrast, distorted barrelette patterns were visible in the AS region of all $8 \mathrm{Mglur} 5^{-1-}$ mice examined. A similar pattern was seen in $\mathrm{VpM}$ of the thalamus. Segregation of barreloids was clearly evident throughout $\mathrm{VpM}$ in all Mglur $5^{+/+}$ $(n=3)$ and in five of seven $M g l u r 5^{+/-}$mice. In the remaining two Mglur5 ${ }^{+/-}$mice, segregation was clearly evident in the region representing the main mystacial vibrissae and partial segregation was seen in the AS region. In Mglur5 ${ }^{-1-}$ mice barreloid segregation appeared normal in the region representing the main mystacial vibrissae, but there was a near-complete loss of segregation in AS region in all five mice examined (Fig. 7). These data indicate that the lack of segregation in the AS of S1 may reflect a loss of whisker-related patterns throughout the trigeminal pathway. 
A
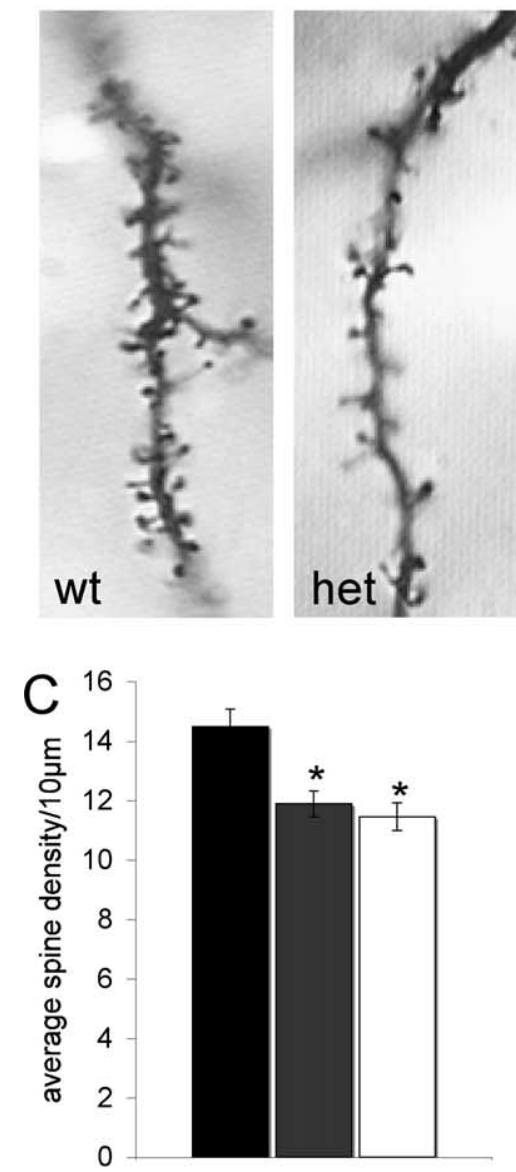

$D$ wt het ko
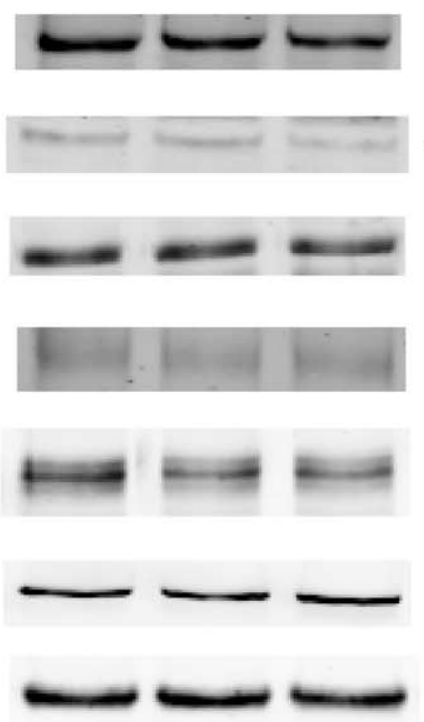

B

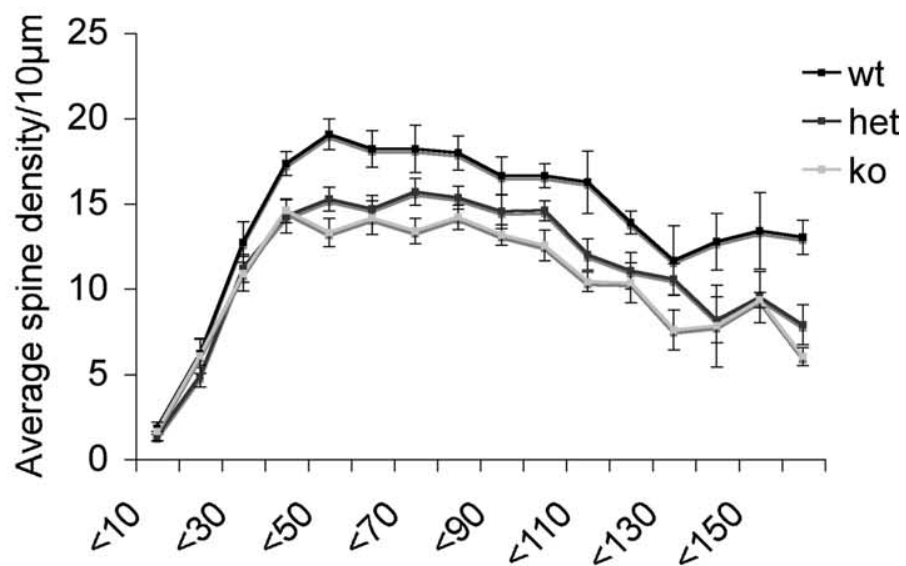

Distance from the cell body $(\mu \mathrm{m})$
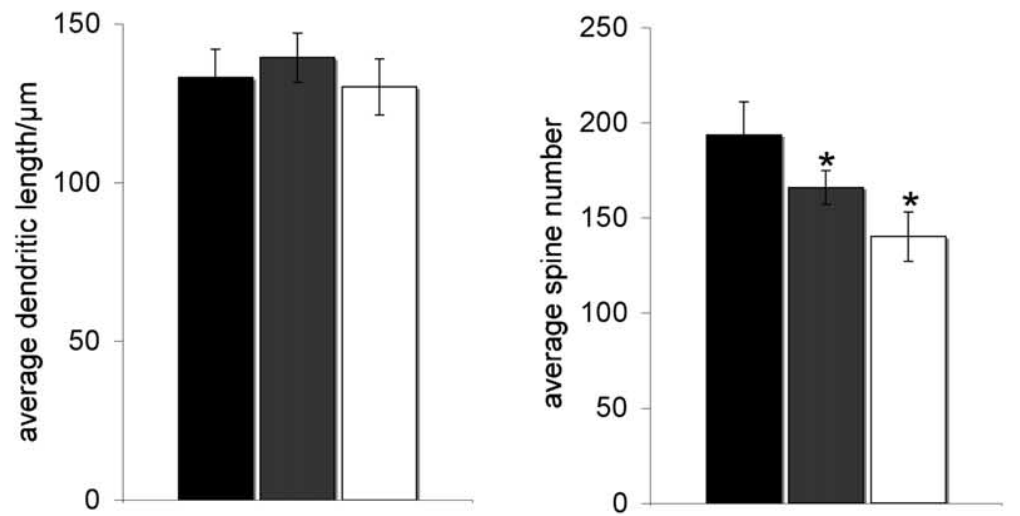

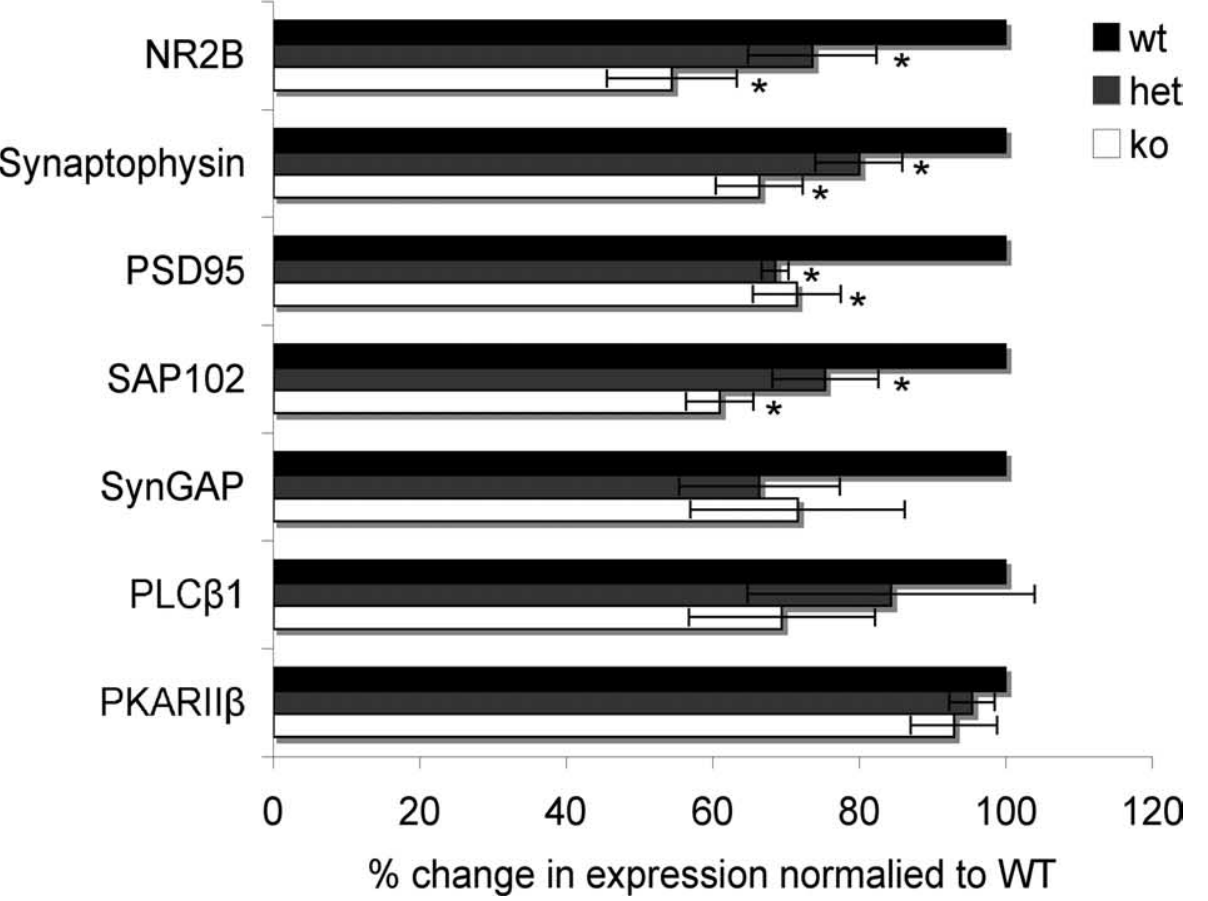

Figure 6. Reduced spine density in layer 4 neurons in $M g l u r 5^{+/-}$and Mglur5 $5^{-1-}$ mice. Analysis of Golgi impregnated layer 4 neurons $(\boldsymbol{A})$ demonstrates a significant decrease in dendritic spine

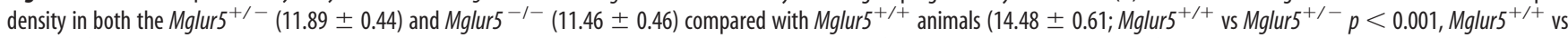
Mglur $\left.^{-1-} p<0.001\right)$ (C). Since average dendritic length was comparable among all genotypes (Mglur $5^{+/+}=133.09 \pm 9.05 \mathrm{vs} \mathrm{Mglur5^{+/- }}=139.37 \pm 7.72$ and Mglur5 ${ }^{-/-}=30.20 \pm$ 8.80), the average spine number per dendrite was also significantly reduced (C) (Average spine counts for Mglur $5^{+/+}=193.62 \pm 17.50$ vs Mglur $5^{+/-}=165.95 \pm 8.72$ and $M g l u r 5^{-/-}=$ $140.14 \pm 13.07 ;$ Mglur $^{+/+}$vs Mglur5 $5^{+/-} p=0.046$, Mglur $^{+/+}$vs Mglur5 $5^{-/-} p<0.001$ ). For all genotypes, 3 dendrites were analyzed (from different neurons) (Figure legend continues.) 

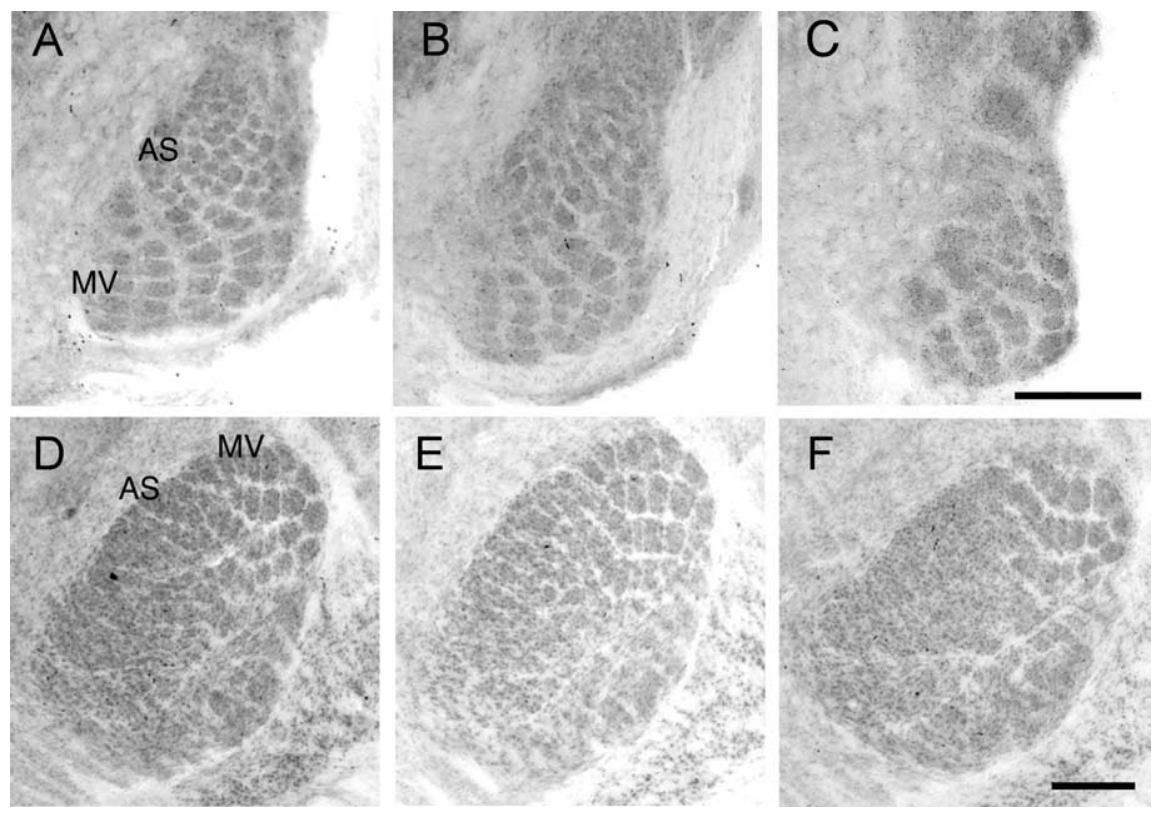

Figure 7. Reduced barrelette and barreloid segregation in the anterior snout representation of PrV and VpM, respectively, at P7. Cytochrome oxidase staining in barrelettes in $\operatorname{PrV}(\boldsymbol{A}-\boldsymbol{C})$ and barreloids in VpM $(\boldsymbol{D}-\boldsymbol{F})$ from Mglur $5^{+/+}(\boldsymbol{A}, \boldsymbol{D}), M g l u r 5^{+/-}(\boldsymbol{B}$, $\boldsymbol{E})$, and Mglur5 $5^{-1-}(\boldsymbol{C}, \boldsymbol{F})$. In Mglur5 ${ }^{-1-}$ mice, whisker-related patches are clearly visible in regions receiving input from the main mystacial vibrissae (MV). In contrast, in the region of PrV that receives input from the anterior snout whiskers (AS), the barrelette pattern is clearly distorted and no segregation is seen in the corresponding region in VpM. Scale bars: $\boldsymbol{C}$ (for $\boldsymbol{A}-\boldsymbol{C}), \boldsymbol{F}$ (for D-F), $250 \mu \mathrm{m}$.

\section{Discussion}

We have previously reported that mGluR5 signaling via PLC- $\beta 1$ regulates the development of whisker patterns within the $\mathrm{S} 1$ of mice (Hannan et al., 2001). We now show that $\mathrm{Mglur}^{+/-}$mice also show a reduction in cellular segregation in layer 4 indicating a dose-dependent regulation of pattern formation. Mglur5 $5^{-1-}$ and $\mathrm{Mglur5}^{+/-}$mice display normal cortical arealization, layer formation, and PMBSF area indicating no general defect in cortical development. Mglur5 ${ }^{-1-}$ and $M g l u r 5^{+/-}$mice show a significant reduction in spine density but no defects in general dendritic complexity indicating a role for this protein in regulating synaptogenesis during cortical development. In support of this suggestion, we found a significant decrease in PSD components and synaptophysin suggesting a decrease in the density of synapses in neocortex. Finally, the pattern of the AS whiskers in the PrV, VpM, and S1 cortex was disrupted in Mglur5 ${ }^{-1-}$ animals suggesting a role for mGluR5 in pattern formation throughout the trigeminal system of mice. Together these data indicate a key

$\leftarrow$

(Figurelegend continued.) from 7 different animals. For all statistical analysis, an $n=7$ (number of animals) was used. The decrease in spine density for both Mglur5 $5^{+/-}$and Mglur5 animals was distributed evenly along the entire dendritic length $(\boldsymbol{B})$. In agreement with the observed decrease in dendritic spine density, Western blot analyses of neocortical homogenates from P7 animals show a decrease in levels of several synaptic proteins $(\boldsymbol{D})$. These include the presynaptic protein synaptophysin (Mglur $5^{+/+}$vs Mglur5 $5^{+/-} p=0.024$, Mglur5 $^{+/+}$vs Mglur5 $\left.^{-1-} p=0.001, n=4\right)$ and the postsynaptic markers PSD-95 (Mglur5 $5^{+/+}$vs

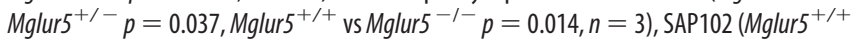
vs Mglur5 $5^{+\prime-} p=0.026$, Mglur5 $5^{+/+}$vs Mglur5 $5^{-1-} p=0.026, n=3$ ), and NR2B (Mglur $^{+/+}$vs Mglur5 $5^{+/-} p=0.013$, Mglur $5^{+/+}$vs Mglur5 $\left.5^{-/-} p=0.001, n=3\right)$. However, levels of SynGAP $(n=3), \operatorname{PLC} \beta 1(n=4)$, and PKARII $\beta(n=4)$ were not significantly different between genotypes. Each sample $(n)$ consisted of 6 pooled cortices from 3 mice. All protein levels were first normalized to $\beta$-actin and then to controls. Asterisks indicate statistical significance relative to Mglur $5^{+/+}$animals. Scale bar, $10 \mu \mathrm{m}$. wt $=M g l u r 5^{+/+}$, het $=$ Mglur5 $^{+/-}$, and ko $=$Mglur5 ${ }^{-1-}$. role for mGluR5 at both early and late stages of neuronal differentiation in the developing trigeminal system.

\section{Heterogeneity of glutamatergic signaling for regulating pattern development in the trigeminal system} Glutamate neurotransmission regulates the development of whisker related patterns throughout the trigeminal system (Erzurumlu and Kind, 2001); however, the glutamate receptors and their downstream signaling pathways are highly heterogeneous both within and between brain regions. mGluR5 is expressed throughout the development of the trigeminal system (Muñoz et al., 1999) and Mglur5 mRNA is expressed in the S1 and VpM during pattern formation (Yamaguchi and Nakanishi, 1998). Mglur5 ${ }^{-1-}$ mice lack whiskerrelated patterns in the AS region throughout the trigeminal system but have relatively normal segregation in the region subserving the main mystacial vibrissae (although segregation of TCAs within PMBSF is reduced). Whether mGluR5 regulates axon segregation in the AS region of $\mathrm{VpM}$ and $\mathrm{S} 1$, or whether the lack of segregation simply reflects the loss of segregation in PrV awaits analysis of region-specific knock-outs. We previously showed that mGluR5 regulates phospholipid hydrolysis in developing cortical neurons through the activation of PLC- $\beta 1$ (Hannan et al., 2001). However in contrast with Mglur5, $P l c-\beta 1$ is not expressed in thalamus (Watanabe et al., 1998) and mice lacking PLC- $\beta 1$ show normal TCA patch formation (Hannan et al., 2001) and normal barreloid and barrelette patterns (our unpublished data). These data indicate that mGluR5 uses different intracellular signaling pathways to mediate cellular and axonal segregation.

NMDA receptors also regulate pattern formation throughout the trigeminal system. Genetic ablation of NMDA receptors prevents whisker-related pattern formation in the brainstem ( $\mathrm{Li}$ et al., 1994), thalamus (Iwasato et al., 1997), and cortex (Iwasato et al., 2000), however the intracellular pathways downstream of NMDA receptors that regulate whisker-related pattern formation vary. For example SynGAP regulates barrel and barreloid formation but not barrelette formation (Barnett et al., 2006b). PKA holoenzymes containing the RIIb-subunit, which tethers PKA to the NMDA receptor via AKAPs, regulate cellular segregation in layer 4 but not barreloid or barrelette formation (Watson et al., 2006, Inan et al., 2006). Furthermore PrkarII $\beta^{-1-}$ mice show poor TCA segregation in the AS region of S1 despite normal segregation in VpM (Watson et al., 2006) indicating a role for PKA in TCA segregation selectively in the AS region of cortex. These findings indicate that while glutamate receptors regulate similar cellular processes (i.e., axon segregation) throughout the trigeminal system, they do so using distinct intracellular pathways.

\section{Role for mGluR5 in regulating spine density}

Glutamate receptors have been shown to regulate spine shape and plasticity in numerous systems. Bear et al. (2004) proposed a role for mGluR5 in the misregulation of spine morphology and 
cognitive development seen in Fragile X syndrome (FXS). In support of this hypothesis, activation of group 1 mGluRs in hippocampal neuronal cultures caused an increase in the frequency of elongated, immature spines (Vanderklish and Edelman, 2002), a phenotype that mimics that seen in patients with FXS in whom the FMR1 gene is transcriptionally silenced (Irwin et al., 2000) and Fmr1 ${ }^{-1-}$ mice (Comery et al., 1997). Dölen et al. (2007) recently showed that genetic reduction of mGluR5 signaling in Fmr1 ${ }^{-1-}$ mice reversed several morphological, behavioral, and physiological consequences of FMRP deletion, including the alteration in spine density. However, while Dölen et al. (2007) found no change in the spine density of layer 3 neurons in V1 of $\mathrm{Mglur}^{+/-}$animals, we find a significant decrease in spine density in layer 4 neurons in S1 of both $\mathrm{Mglur}^{+/-}$and $M g l u r 5^{-1-}$ animals. These differences are likely due to the difference in cell type examined in the two studies. In support of this hypothesis, Dölen et al. (2007) did report an absence of ocular dominance plasticity to monocular deprivation in $\mathrm{Mglur}^{+/-}$animals, a result that would be consistent with altered synapse plasticity in layer 4 neurons. Furthermore our findings are still consistent with an interaction between mGluR5 and FMRP signaling pathways in the regulation of spine density.

H.-C. Lu et al. found an increase in spine density on layer 4 pyramidal neurons in Mglur $5^{-1-}$ mice (W.-C. She, C. Quairiaux, C.-C. Chen, M. J. Albright, Y.-C. Wang, D. E. Sanchez, J. P. Carson, J. C. Brumberg, P.-S. Chang, E. Welker, and H.-C. Lu, unpublished observations). It was not possible to determine the cell type of our neurons since analysis was performed in tangential sections, however, given that spiny stellate and atypical pyramidal neurons form the predominant cell types in layer 4 of rats (Staiger et al., 2004), it is likely that we are simply sampling from different neuronal types. These data indicate that mGluR5 plays distinct roles in regulating spine development in different classes of cortical neurons.

\section{Synaptic activity and barrel formation}

The relationship between neuronal activity, glutamate receptors and barrel formation remains unclear. While studies using transgenic mice clearly demonstrate a role for glutamate receptors in the patterning of the trigeminal system (Erzurumlu and Kind, 2001), whether patterns of activity are needed to instruct barrel development is unknown. Several findings, however, indicate that while glutamate receptors are necessary for barrel formation, spontaneous release of glutamate may be sufficient to allow TCA segregation and cellular segregation in layer 4 (Van der Loos and Woolsey, 1973; Watson et al., 2006). First cellular segregation in layer 4 still occurs around the fused TCAs that result following row $\mathrm{C}$ follicle ablation despite a complete loss of peripheral receptors (Van der Loos and Woolsey, 1973). Furthermore, while mice lacking the RII $\beta$ subunit of PKA show decreased cellular segregation (Inan et al., 2006; Watson et al., 2006), a loss of LTP at TCA synapses (Inan et al., 2006) and decreased AMPA receptor insertion into the PSD in S1 (Watson et al., 2006), AMPA receptors do not appear to regulate barrel formation (Watson et al., 2006). These data argue against a role for patterns of activity and synaptic plasticity as being key regulators of pattern development in layer 4 of S1. Instead the spontaneous release of glutamate from TCA bundles may be sufficient for cellular segregation, suggesting more of a neurotropic role for glutamate in the early anatomical development of barrels.

There is also confusion over the role of glutamate neurotransmission and patterns of activity in lesion-induced plasticity. Pharmacological blockade of NMDA receptor or TTX infusion does not alter TCA segregation (importantly, layer 4 cell segregation was not examined) (Fox et al., 1996) and genetic deletion of NR1 (Iwasato et al., 2000), PKARIIb (Inan et al., 2006), or cortical AC1 (Iwasato et al., 2008) does not prevent the fusion of TCAs following Row C-follicle ablation. Furthermore, the sensitive period for lesion-induced plasticity and barrel development can be dissociated, indicating distinct cellular mechanisms drive the two processes (Rebsam et al., 2005). Together, these findings suggest that while glutamate neurotransmission is necessary for barrel formation, it is unlikely to mediate the large morphological changes seen following lesion-induced plasticity (but see Takasaki et al., 2008). In contrast, patterns of activity are necessary to induce synaptic strengthening/weakening (Crair and Malenka, 1995), spine maturation (Lendvai et al., 2000), and physiological development and plasticity (Fox, 2002).

Glutamate neurotransmission is essential for experiencedependent development and plasticity in sensory systems. However, it now appears there may be an earlier role for glutamate as a neurotropic agent at early stages of neuronal development that is independent of their classical role as mediators of synaptic plasticity (Van der Loos and Woolsey, 1973; Watson et al., 2006). At these early stages when synapses are first forming, glutamate may be being used to relay position information from a set of incoming axons to set up cortical patterns. Furthermore, while glutamate receptors may be necessary for the refinement of dendritic trees or synapses, the emerging evidence from transgenic animals lacking these receptors or their downstream signaling enzymes indicates that the development of dendritic complexity and spine density is largely a glutamate-independent process (Figs. 5, 6) (Datwani et al., 2002; Inan et al., 2006). Nonetheless, it is clear that the role that glutamate plays in the establishment of cortical connectivity and plasticity is crucial to normal cognitive development as the genes encoding several PSD proteins are mutated in various cognitive disorders (Tarpey et al., 2004; Grant et al., 2005). Dissecting specific cellular processes regulated by different components of the PSD will be important for understanding the etiology of the diseases they underlie.

\section{References}

Barnett MW, Watson RF, Kind PC (2006a) Pathways to barrel development. In: Development and plasticity in sensory thalamus and cortex (Erzurumlu R, Guido W, Molnar Z, eds), pp 138-157. New York: Springer.

Barnett MW, Watson RF, Vitalis T, Porter K, Komiyama NH, Stoney PN, Gillingwater TH, Grant SGN, Kind PC (2006b) Synaptic Ras GTPase activating protein regulates pattern formation in the trigeminal system of mice. J Neurosci 26:1355-1365.

Bear MF, Huber KM, Warren ST (2004) The mGluR theory of fragile X mental retardation. Trends Neurosci 27:370-377.

Comery TA, Harris JB, Willems PJ, Oostra BA, Irwin SA, Weiler IJ, Greenough WT (1997) Abnormal dendritic spines in fragile X knockout mice: maturation and pruning deficits. Proc Natl Acad Sci US A 94:5401-5404.

Crair MC, Malenka RC (1995) A critical period for long-term potentiation at thalamocortical synapses. Nature 375:325-328.

Datwani A, Iwasato T, Itohara S, Erzurumlu RS (2002) NMDA receptordependent pattern transfer from afferents to postsynaptic cells and dendritic differentiation in the barrel cortex. Mol Cell Neurosci 21:477-492.

Dölen G, Osterweil E, Rao BS, Smith GB, Auerbach BD, Chattarji S, Bear MF (2007) Correction of fragile X syndrome in mice. Neuron 56:955-962.

Dunkley PR, Jarvie PE, Heath JW, Kidd GJ, Rostas JA (1986) A rapid method for isolation of synaptosomes on Percoll gradients. Brain Res 372:115-129.

Erzurumlu RS, Kind PC (2001) Neural activity: sculptor of "barrels" in the neocortex. Trends Neurosci 24:589-595.

Fox K (2002) Anatomical pathways and molecular mechanisms for plasticity in the barrel cortex. Neuroscience 111:799-814. 
Fox K, Schlaggar BL, Glazewski S, O’Leary DD (1996) Glutamate receptor blockade at cortical synapses disrupts development of thalamocortical and columnar organization in somatosensory cortex. Proc Natl Acad Sci U S A 93:5584-5589.

Grant SG, Marshall MC, Page KL, Cumiskey MA, Armstrong JD (2005) Synapse proteomics of multiprotein complexes: en route from genes to nervous system diseases. Hum Mol Genet 14:R225-R234.

Hannan AJ, Blakemore C, Katsnelson A, Vitalis T, Huber KM, Bear M, Roder J, Kim D, Shin HS, Kind PC (2001) Phospholipase C- $\beta 1$, activated via mGluRs, mediates activity-dependent differentiation in cerebral cortex. Nat Neurosci 4:282-288.

Inan M, Lu HC, Albright MJ, She WC, Crair MC (2006) Barrel map development relies on PKARII $\beta$-mediated cAMP signaling. J Neurosci 26:4338-4349.

Irwin SA, Galvez R, Greenough WT (2000) Dendritic spine structural anomalies in fragile- $\mathrm{X}$ mental retardation syndrome. Cereb Cortex 10:1038-1044.

Iwasato T, Erzurumlu RS, Huerta PT, Chen DF, Sasaoka T, Ulupinar E, Tonegawa S (1997) NMDA receptor-dependent refinement of somatotopic maps. Neuron 19:1201-1210.

Iwasato T, Datwani A, Wolf AM, Nishiyama H, Taguchi Y, Tonegawa S, Knöpfel T, Erzurumlu RS, Itohara S (2000) Cortex-restricted disruption of NMDAR1 impairs neuronal patterns in the barrel cortex. Nature 406:726-731.

Iwasato T, Inan M, Kanki H, Erzurumlu RS, Itohara S, Crair MC (2008) Cortical adenylyl cyclase 1 is required for thalamocortical synapse maturation and aspects of layer IV barrel development. J Neurosci 28:5931-5943.

Killackey HP, Belford GR (1979) The formation of afferent patterns in the somatosensory cortex of the neonatal rat. J Comp Neurol 183:285-303.

Kind PC, Neumann PE (2001) Plasticity: downstream of glutamate. Trends Neurosci 24:553-555.

Lee LJ, Iwasato T, Itohara S, Erzurumlu RS (2005) Exuberant thalamocortical axon arborization in cortex-specific NMDAR1 knockout mice. J Comp Neurol 485:280-292.

Lendvai B, Stern EA, Chen B, Svoboda K (2000) Experience-dependent plasticity of dendritic spines in the developing rat barrel cortex in vivo. Nature 404:876-881.

Li Y, Erzurumlu RS, Chen C, Jhaveri S, Tonegawa S (1994) Whisker-related neuronal patterns fail to develop in the trigeminal brainstem nuclei of NMDAR1 knockout mice. Cell 76:427-437.

Muñoz A, Liu XB, Jones EG (1999) Development of metabotropic glutamate receptors from trigeminal nuclei to barrel cortex in postnatal mouse. J Comp Neurol 409:549-566.

Rebsam A, Seif I, Gaspar P (2002) Refinement of thalamocortical arbors and emergence of barrel domains in the primary somatosensory cortex: a study of normal and monoamine oxidase a knock-out mice. J Neurosci 22:8541-8552.

Rebsam A, Seif I, Gaspar P (2005) Dissociating barrel development and lesion-induced plasticity in the mouse somatosensory cortex. J Neurosci 25:706-710.

Rodríguez-Moreno A, Sistiaga A, Lerma J, Sánchez-Prieto J (1998) Switch from facilitation to inhibition of excitatory synaptic transmission by group 1 mGluR desensitization. Neuron 21:1477-1486.

Romano C, Sesma MA, McDonald CT, O’Malley K, Van den Pol AN, Olney JW (1995) Distribution of metabotropic glutamate receptor mGluR5 immunoreactivity in rat brain. J Comp Neurol 355:455-469.

Spires TL, Molnár Z, Kind PC, Cordery PM, Upton AL, Blakemore C, Hannan AJ (2005) Activity-dependent regulation of synapse and dendritic spine morphology in developing barrel cortex requires phospholipase C- $\beta 1$ signalling. Cereb Cortex 15:385-393.

Staiger JF, Flagmeyer I, Schubert D, Zilles K, Kötter R, Luhmann HJ (2004) Functional diversity of layer IV spiny neurons in rat somatosensory cortex: quantitative morphology of electrophysiologically characterized and biocytin labeled cells. Cereb Cortex 14:690-701.

Takasaki C, Okada R, Mitani A, Fukaya M, Yamasaki M, Fujihara Y, Shirakawa T, Tanaka K, Watanabe M (2008) Glutamate receptors regulate lesion-induced plasticity in the developing somatosensory cortex. J Neurosci 28:4995-5006.

Tarpey P, Parnau J, Blow M, Woffendin H, Bignell G, Cox C, Cox J, Davies H, Edkins S, Holden S, Korny A, Mallya U, Moon J, O’Meara S, Parker A, Stephens P, Stevens C, Teague J, Donnelly A, Mangelsdorf M, et al. (2004) Mutations in the DLG3 gene cause nonsyndromic X-linked mental retardation. Am J Hum Genet 75:318-324.

Vanderklish PW, Edelman GM (2002) Dendritic spines elongate after stimulation of group 1 metabotropic glutamate receptors in cultured hippocampal neurons. Proc Natl Acad Sci U S A 99:1639-1644.

Van der Loos H, Woolsey TA (1973) Somatosensory cortex: structural alterations following early injury to sense organs. Science 179:395-398.

Watanabe M, Nakamura M, Sato K, Kano M, Simon MI, Inoue Y (1998) Patterns of expression for the mRNA corresponding to the four isoforms of phospholipase Cbeta in mouse brain. Eur J Neurosci 10:2016-2025.

Watson RF, Abdel-Majid RM, Barnett MW, Willis BS, Katsnelson A, Gillingwater TH, McKnight GS, Kind PC, Neumann PE (2006) Involvement of protein kinase A in patterning of the mouse somatosensory cortex. J Neurosci 26:5393-5401.

White EL, Weinfeld L, Lev DL (1997) A survey of morphogenesis during the early postnatal period in PMBSF barrels of mouse SmI cortex with emphasis on barrel D4. Somatosens Mot Res 14:34-55.

Wong-Riley M (1979) Changes in the visual system of monocularly sutured or enucleated cats demonstrable with cytochrome oxidase histochemistry. Brain Res 171:11-28.

Woolsey TA, Van der Loos H (1970) The structural organization of layer 4 in the somatosensory region (SI) of the mouse cerebral cortex. Brain Res 17:205-242.

Yamaguchi S, Nakanishi S (1998) Regional expression and regulation of alternative forms of mRNAs derived from two distinct transcription initiation sites of the rat mGluR5 gene. J Neurochem 71:60-68. 